CDD: 029.753

\title{
ANÁLISE DE CITAÇÕES NA ÁREA DE COMUNICAÇÃO E INFORMAÇÃO: O CASO DE UM PROGRAMA DE PÓS-GRADUAÇÃO
}

CITATION ANALYSIS IN COMUNICATION AND INFORMATION AREA: THE CASE OF A GRADUATE PROGRAM

\author{
Zizil Arledi Glienke Nunez ${ }^{1}$ \\ Ana Maria Mielniczuk de Moura ${ }^{2}$
}

Resumo: O presente estudo bibliométrico analisa o uso das teses e dissertações de um programa de pós-graduação. O objetivo é verificar se os trabalhos em questão são citados, além de observar a possível existência de redes de citações. A partir da coleta nos buscadores Google e Google Acadêmico, o tratamento dos dados foi feito no software BrOffice Calc, UCINET e NETDRAW. Constata que a área da Comunicação acumulou maior número de trabalhos e citações nos últimos anos. Os trabalhos foram mais citados por doutores e pela Universidade Federal do Rio Grande do Sul. As redes identificadas têm maior participação de autores regionais com alguma exceções. Considera que estes trabalhos são utilizados em âmbito nacional.

Palavras-chave: Análise de Citações. Análise de Redes Sociais. Bibliometria. PPGCOM. UFRGS.

Abstract: This bibliometric study analyzes the use of theses and dissertations of a postgraduate program. The objective is to verify if the works in question are cited, besides observing the possible existence of networks citations. From the collection in search engines Google and Google Scholar, the data processing was done using BrOffice Calc software, UCINET and NETDRAW. It is noted that the Communication area accumulates more papers and citations in recent years. The papers were more cited by doctors and by Rio Grande do Sul Federal University. The most of the participants of the identified networks are regional authors, with some exceptions. It appears that these works are used nationally.

Keywords: Citation Analysis. Social Network Analysis. Bibliometrics. PPGCOM. UFRGS.

\footnotetext{
${ }^{1}$ Mestranda em Comunicação e Informação pela UFRGS. Bacharel em Biblioteconomia pela UFRGS. Universidade Federal do Rio Grande do Sul. Brasil. E-mail: zizil.arledi@ gmail.com

${ }^{2}$ Doutora em Comunicação e Informação pela UFRGS. Professora adjunta e Chefe do Departamento de Ciências da Informação da UFRGS. Universidade Federal do Rio Grande do Sul. Brasil. E-mail: ana.mmoura@uol.com.br
} 


\section{INTRODUÇÃO}

Este estudo consiste em uma análise de citações dos trabalhos acadêmicos de um Programa de Pós-Graduação das áreas de Comunicação e Informação, de modo a verificar se estes são utilizados pelo meio científico aos quais pertencem, bem como analisar as redes existentes a partir das citações constatadas.

Para contextualizar o estudo, é preciso relembrar a importância do meio acadêmico para o a ciência no país. Castro (1985) propôs que o desenvolvimento da pesquisa no Brasil se deu em três fases, todas na segunda metade do século XX, sendo a primeira entre as décadas de 1950 e 1960, onde se deu ênfase à formação de pessoas; em seguida essa ênfase passou a ser a criação dos cursos e a partir da década de 1980, deu-se finalmente maior atenção à pesquisa. Soma-se o fato de que

\footnotetext{
"no período de 1994 a 2001 houve um crescimento de 31\% no número de alunos nos programas de mestrado, atingindo um total de 60,3 mil estudantes nesse último ano. No caso do doutorado, o número de alunos cresceu em 73\% no período, atingindo 32,7 mil estudantes em 2001" (PORTO; REGNIER, 2003, p. 78).
}

Unido a outros fatores, o crescimento da pós-graduação ao longo do tempo contribuiu para o aumento da produção científica acadêmica, que com as tecnologias atuais estão ao alcance de qualquer pessoa mediante o acesso à internet. $\mathrm{O}$ rápido acesso à literatura acadêmica, por sua vez, facilitou o uso deste tipo de documento.

\section{METODOLOGIA}

Uma vez que o conhecimento é cumulativo, velhas ideias podem ser renovadas e aprimoradas, levando-o à níveis cada vez mais elevados. (MEADOWS, 1999). Nesta perspectiva se baseiam as citações, cujos estudos correlatos permitem medir o impacto e a visibilidade dos autores de uma rede, a linha de pensamento mais difundida entre estes ou os tipos de documentos mais utilizados, a fim de descobrir teorias e metodologias consolidadas (VANZ; CAREGNATO, 2003). O número das citações também avalia o desempenho científico dos pesquisadores (BUFREM; PRATES, 2005), além de refletir o impacto dos artigos ou assuntos mais citados na comunidade científica. (MACIAS-CHAPULA, 1998). Callon, Courtial e Penan 
(1995) acrescentam que análises das relações baseadas em citações podem conduzir a estudos detalhados de uma rede onde se encontra um pesquisador ou equipe de pesquisadores. Neste sentido é possível verificar ainda sua visibilidade, que segundo Rousseau (1998) é um dos aspectos importantes da pesquisa científica.

O trabalho apresenta metodologia bibliométrica, tratando dos aspectos quantitativos da produção, disseminação e uso da informação registrada (PRITCHARD $^{3}$, 1969, p. 348-9 apud MACIAS-CHAPULA, 1998). O corpus da pesquisa se compõe da totalidade de dissertações e teses defendidas no Programa de Pós-Graduação em Comunicação e Informação (PPGCOM) da Universidade Federal do Rio Grande do Sul entre os anos de 2004 a 2009, bem como dos trabalhos que os citaram, até o ano de 2009. Tal característica reforça o contexto bibliométrico da pesquisa, pois "a bibliometria estuda a organização dos setores científicos e tecnológicos a partir de fontes bibliográficas e patentes para identificar os atores, suas relações e suas tendências." "(SPINAK, 1998, p. 143, tradução nossa). Além disso, reforça o autor, trabalha com várias medições da literatura, de documentos e outros meios de comunicação. Para demarcar o intervalo temporal dos trabalhos analisados, optou-se como início 2004, ano em que as primeiras teses foram defendidas, e como data final, o ano de 2009, ano anterior ao da coleta dos dados.

O indicador de citações é um dado que revela a recepção da publicação de um autor pelos seus pares, mas não indica necessariamente qualidade ou prestígio. (GLÄNZEL, 2003). Nesta perspectiva surge a necessidade de complementar o estudo de citações através da análise de outros indicadores, uma vez que a quantificação por si só pode acarretar em interpretações errôneas. Para os trabalhos do Programa de Pós-Graduação, foram definidos como indicadores o $\mathrm{n}^{\mathrm{o}}$ de citações recebidas por ano, $\mathrm{n}^{\circ}$ de citações por área (Comunicação e Informação, considerando uma citação por autor), e o tempo decorrido entre publicação e citação. Para os trabalhos citantes, foram definidos como indicadores o autor, tipologia do documento, titulação acadêmica do autor, vínculo institucional do autor (considerando o vínculo informado

\footnotetext{
${ }^{3}$ PRITCHARD, A. Statistical Bibliography or Bibliometrics? Journal of Documentation, n. 25, p. 348-9, 1969.

${ }^{4}$ Tradução de: "La bibliometría estudia la organización de los sectores científicos y tecnológicos a partir de las fuentes bibliográficas y patentes para identificar a los actores, a sus relaciones, y a sus tendencias."
} 
no artigo, ou no ano relativo à citação de acordo com o Currículo Lattes), Qualis dos periódicos e o idioma.

A primeira etapa do estudo consistiu na coleta das teses e dissertações no site do Programa de Pós-Graduação ${ }^{5}$. Na segunda etapa, foi realizada uma busca no Google e Google Acadêmico, por trabalhos que citassem a produção acadêmica em questão. A expressão de busca foi constituída pelo título, autor e ano de cada um dos trabalhos, em diferentes combinações por vez, como forma de recuperar a maior quantidade de dados úteis possíveis. A escolha da base Google se deu pelo fato de que em levantamentos em bases bibliográficas tradicionais como Web of Science, Scopus e Scielo, não foram recuperadas citações dos trabalhos do PPGCOM à época da coleta de dados. Web of Science e Scopus possuem como característica a preferência pelo idioma inglês, fato que pode ter influenciado estes resultados. Além disso, os procedimentos de seleção de revistas da WoS "são parciais e não são adequados nem suficientes para avaliar a C\&T dos países e desenvolvimento." (SPINAK, 1998, p.146, tradução nossa). Sendo assim, o uso destas bases poderia implicar em resultados não muito realistas ou justos para fundamentar um estudo de citações dos trabalhos selecionados para este estudo.

Para o tratamento dos dados e elaboração das matrizes de rede, foi utilizado o software BrOffice Calc e para a criação dos mapas das redes de citação, as matrizes foram exportadas para os softwares UCINET e NETDRAW.

\section{ANÁLISE DOS TRABALHOS DEFENDIDOS NO PROGRAMA DE PÓS- GRADUAÇÃO EM COMUNICAÇÃO E INFORMAÇÃO DA UNIVERSIDADE FEDERAL DO RIO GRANDE DO SUL}

De acordo com os resultados obtidos, a área da Comunicação foi a que acumulou maior número de citações de outros trabalhos, com 107 citações distribuídas entre 35 citações de teses e 72 citações de dissertações. Já a área da Informação obteve 10 citações. Entretanto, a área da Comunicação possui no total 72 trabalhos defendidos, enquanto a área da Informação possui 21.

\footnotetext{
${ }^{5}$ http://www.ppgcom.ufrgs.br

${ }^{6}$ Tradução de: "son parciales y no son adecuados ni suficientes para evaluar la C\&T de los países en vías de desarrollo."
} 
O Gráfico 1 apresenta os dados das citações por ano. De forma geral, pôde-se verificar que os trabalhos mais citados foram os mais antigos, fato que demonstra que a visibilidade de um documento tende a aumentar em detrimento do tempo decorrente após sua publicação. Em relação às dissertações, verificou-se os anos de 2004 e 2005 como os mais frutíferos para citações. Em ambos os casos constatou-se que a distribuição de citações ao longo dos anos é irregular.

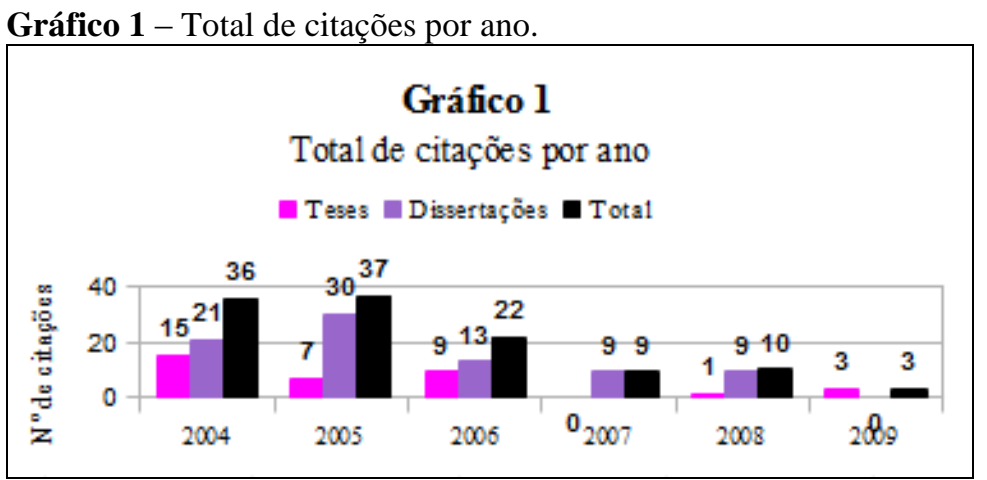

Fonte: dados das autoras.

O tempo decorrido entre publicação e citação é um indicador importante para prever a média de tempo que um trabalho levará para ser citado. Deve-se considerar neste contexto a questão do tema, pois "artigos questionáveis que tratam de temas menos importantes provavelmente serão ignorados e não citados.” (MEADOWS, 1999, p. 89). Neste sentido, certos temas podem se tornar obsoletos com o passar do tempo, principalmente na área da Comunicação, que trabalha constantemente com novas mídias e tecnologias, o que pode explicar a irregularidade das citações.

Gráfico 2 - Intervalo de tempo entre publicação e citação.

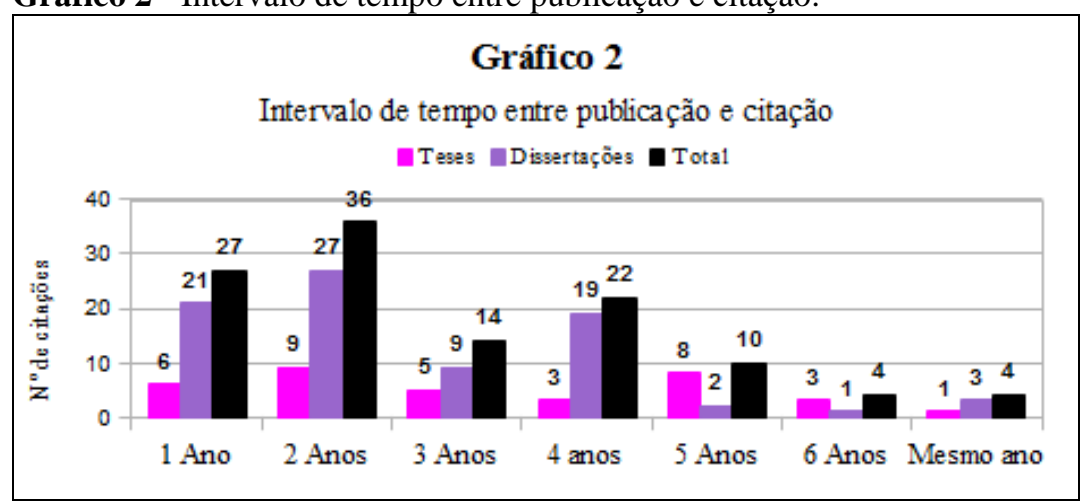

Fonte: Dados das autoras. 
Percebe-se no Gráfico 2 que o intervalo de tempo frequente foi de 2 anos, tanto para as teses quanto para as dissertações, observando-se as medianas entre os intervalos 2-5 anos (teses) e 1-2 (dissertações). O resultado obtido aproxima-se com o pico de intervalo de citação de três anos, mencionado por Maltrás-Barba (2003).

\section{ANÁLISE DOS TRABALHOS CITANTES}

Nos gráficos 3 e 4, os eixos verticais indicam os autores citantes, enquanto os eixos horizontais representam o número de citações feitas por cada um. Foi possível verificar no Gráfico 3 que a autora mais representativa nas citações das teses foi a pesquisadora $\mathbf{J}$. Outros autores significativos foram os pesquisadores $\mathbf{G}, \mathbf{W}$ e $\mathbf{Z}$. Percebe-se que as teses obtiveram maior visibilidade regional, visto que os pesquisadores sobressalentes no gráfico atuam no Rio Grande do Sul.

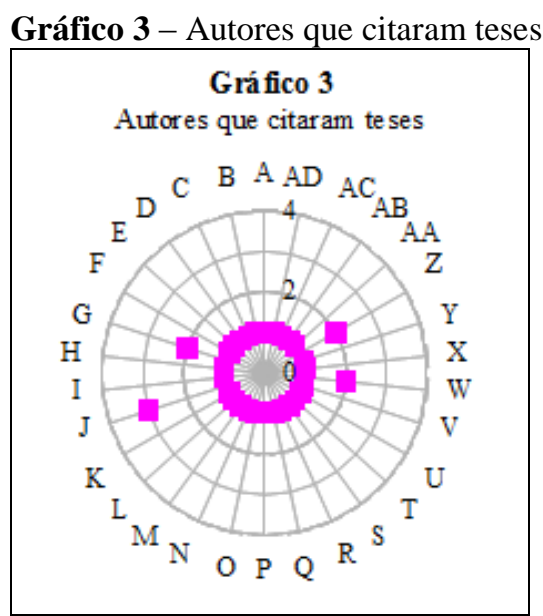

Fonte: dados das autoras.

Em função da legibilidade, o Gráfico 4 representa apenas os pesquisadores que citaram dissertações no mínimo duas vezes. Conforme os dados do gráfico, o pesquisador $\mathbf{A}$ foi quem mais realizou citações. Depois deste, os que mais se destacam pelas citações feitas são os pesquisadores $\mathbf{B}$ e $\mathbf{M}$. Estes números indicam a regionalização das citações, pois todos os pesquisadores que se destacam em número de citações feitas atuam no Rio Grande do Sul. 
Gráfico 4 - Autores que mais citaram dissertações.

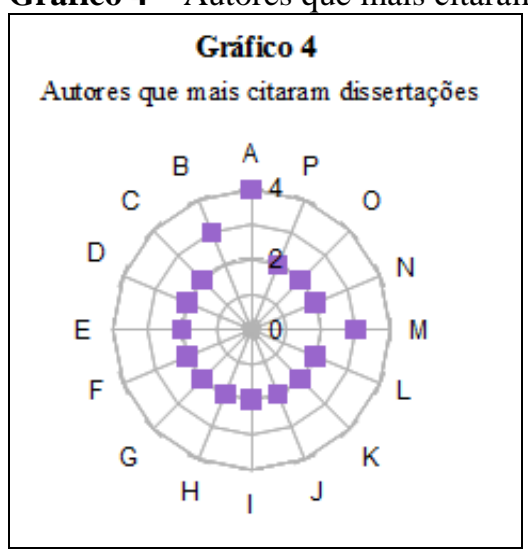

Fonte: dados das autoras.

Para análise da titulação, foi observada a titulação que o autor citante possuía no ano em que citou a tese ou dissertação. Pode-se observar que de uma forma geral, quem mais citou estes trabalhos foram Doutores e Mestres, com respectivamente 39 e 25 citações.

Gráfico 5 - Titulação acadêmica dos autores.

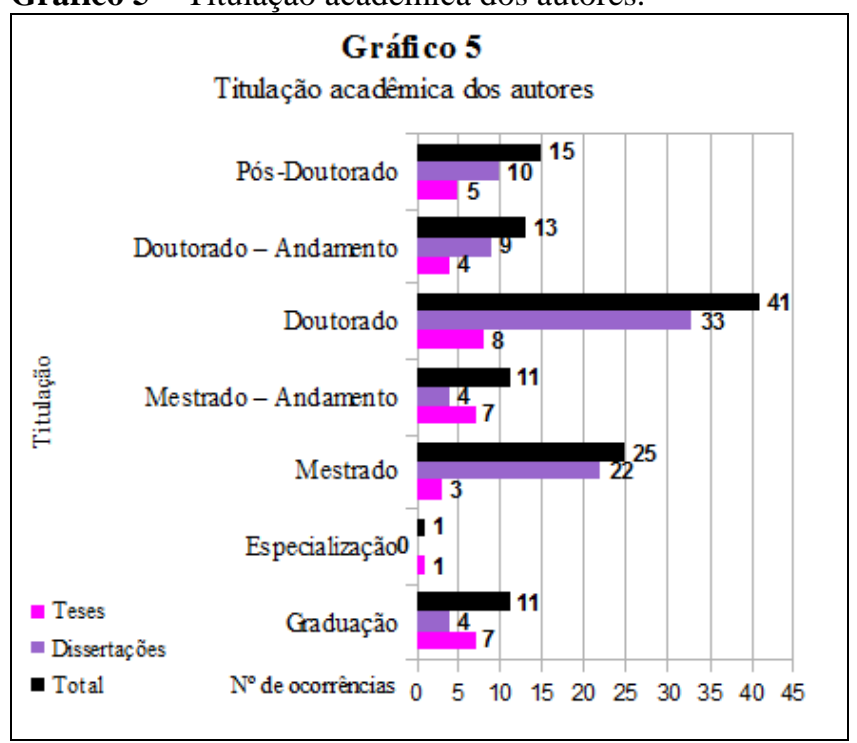

Fonte: dados das autoras.

Observa-se no Gráfico 5 que as dissertações se mostraram mais visíveis que as teses, pois foram citadas em sua maioria em trabalhos de pesquisadores com maiores 
titulações, geralmente mais valorizados. A importância atribuída a este tipo de literatura se deve à qualificação exigida pelos trabalhos acadêmicos de pós-graduação e que segundo Kobashi e Santos (2006), refletem as atividades de pesquisa dentro de uma instituição.

Já o local de atuação dos autores citantes foi analisado de acordo com o Gráfico 6. A partir dos valores indicados, pode-se perceber que Porto Alegre e Santa Maria, no Rio Grande do Sul, foram as cidades de onde se originam a maior parte das citações. Cabe ressaltar que ambas acolhem as duas universidades federais mais importantes do estado, além de possuírem pós-graduação em Comunicação e Informação, o que pode justificar o uso dos trabalhos da Universidade Federal do Rio Grande do Sul pela Universidade Federal de Santa Maria.

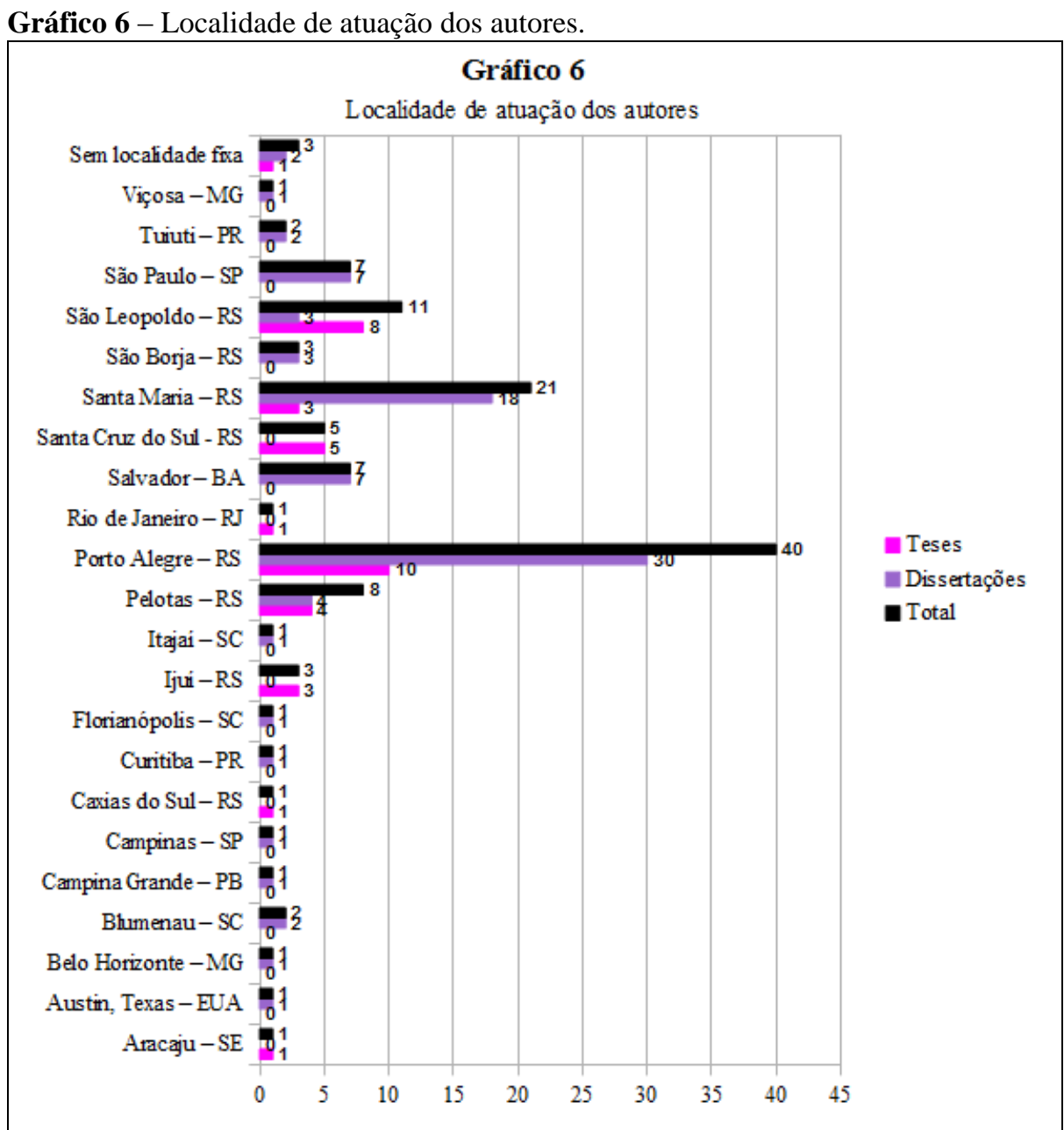

Fonte: dados das autoras. 
Os tipos de publicação foram separados no Gráfico 7 e referem-se aos diferentes suportes onde os documentos foram publicados, sendo divididos conforme os tipos encontrados durante a coleta de dados: anais de eventos (publicações que divulgam as pesquisas apresentadas em um evento), trabalhos acadêmicos (teses, dissertações e monografias) e periódicos (publicações que divulgam os artigos científicos, resenhas, dossiês e ensaios).

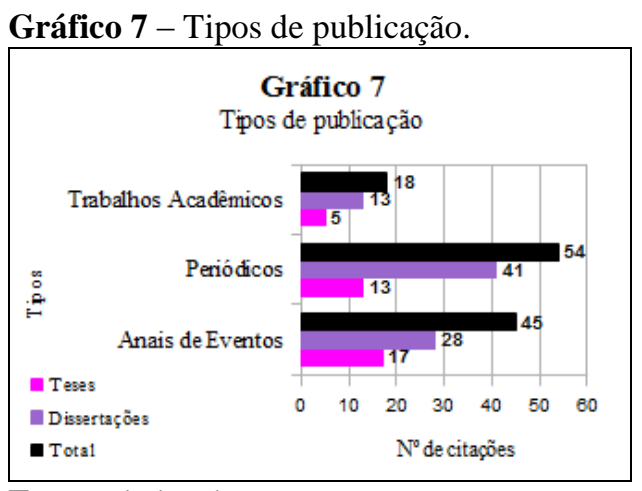

Fonte: dados das autoras.

Verifica-se a partir deste gráfico que no total geral, os periódicos e os anais de eventos foram os tipos de publicação que mais originaram citações. $\mathrm{O}$ grupo das teses foi mais citado por trabalhos em anais de eventos, sendo o Congresso Brasileiro de Ciências da Comunicação o evento mais representativo, seguido do Simpósio da ABCiber, de acordo com o Gráfico 8. O domínio de eventos da área da Comunicação se explica pelo fato de que a totalidade das teses do estudo pertencem a esta área.

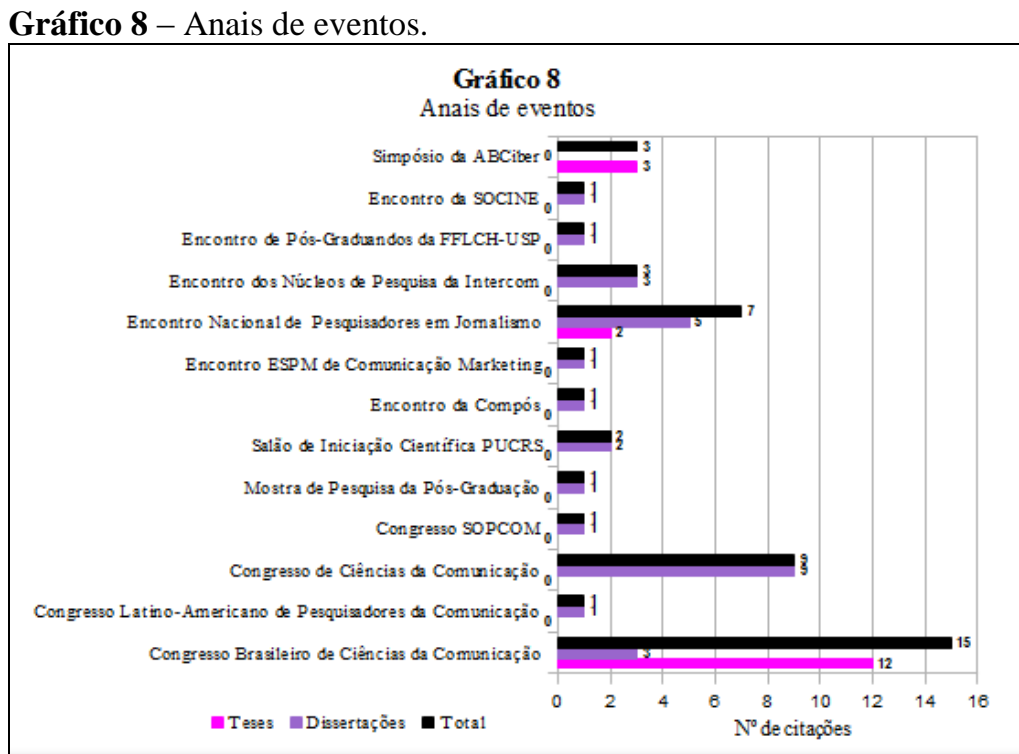


Fonte: dados das autoras.

Para o grupo das dissertações, o evento que originou mais citações foi o Congresso de Ciências da Comunicação e em seguida, o Encontro Nacional de Pesquisadores em Jornalismo. Pode-se ressaltar que a maior parte das citações provenientes dos trabalhos apresentados em eventos foram referentes às teses da área da Comunicação. Obter maior divulgação através de eventos pode ser um fator negativo para as teses citadas, pois Meadows (1999) coloca que a maior parte dos cientistas costuma não dar muito valor à produção científica de congressos.

Já as análises dos periódicos citantes são importantes devido ao fato de que "a visibilidade da produção científica de um país, de uma universidade, de uma área temática, de um grupo de pesquisa e de um pesquisador individual está relacionada diretamente com a visibilidade dos periódicos onde são publicados os resultados das suas pesquisas" (PACKER; MENEGHINI, 2006, p. 237). Isto significa que a qualidade de um artigo se relaciona com a qualidade atribuída ao periódico onde o mesmo é publicado. De uma forma geral pode-se dizer que as citações em periódicos são satisfatórias, pois foram provenientes também de quatro revistas de visibilidade internacional ou estrangeiras, como a Brazilian Journalism Research, brasileira, a M@gm@, italiana, a Faro, chilena, e a Revista Latinoamericana de Estudios del Discurso, venezuelana. Além disso, na questão dos periódicos percebe-se uma diferença entre as teses e as dissertações, pois além de as primeiras serem mais visíveis por terem sido citadas em periódicos estrangeiros, foram também citadas em periódicos mais qualificados, beneficiando os autores citados, uma vez que o pesquisador geralmente procura levar em conta a qualidade do periódico que lê ou no qual publica seus artigos. (TRZESNIAK, 2006). 


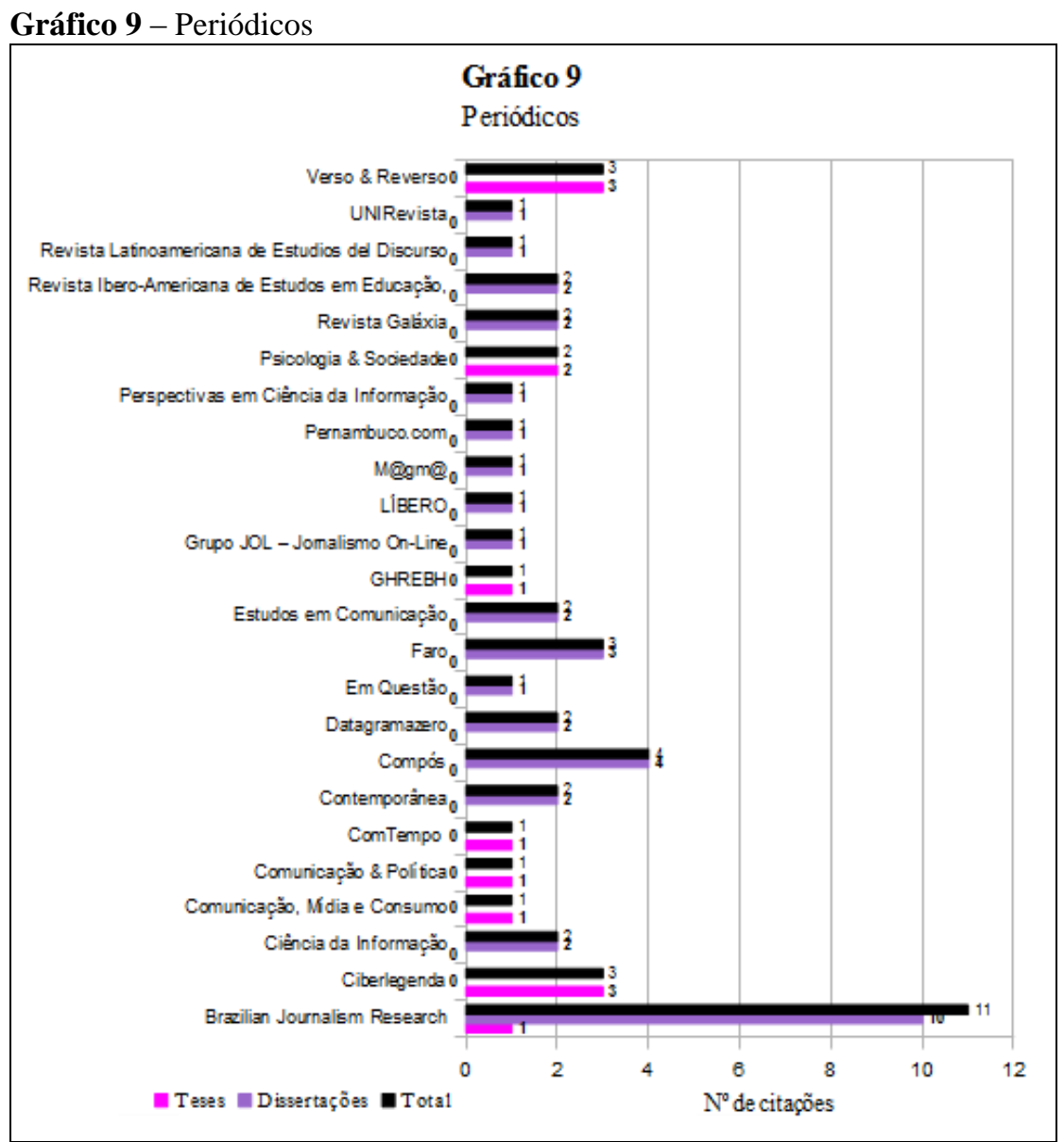

Fonte: dados das autoras.

O grupo mais citado em publicações periódicas foi o das dissertações, sendo a maior parte das citações contidas na revista Brazilian Journalism Research, da Universidade de Brasília, seguida da revista E-Compós, da Associação Nacional dos Programas de Pós-Graduação em Comunicação e da revista científica Faro, da Universidad de Playa Ancha, localizada no Chile. No caso das citações de teses em periódicos, merecem destaque as revistas Ciberlegenda e Verso \& Reverso. De forma geral, as teses foram citadas por periódicos de Qualis B3 e B5, com 4 citações, seguidos do Qualis A2, com 2 citações.

Em relação às citações em periódicos, as dissertações encontram-se em melhor situação por terem sido mais citadas por periódicos de Qualis B2, com 14 citações, Qualis B1, com 10 citações e Qualis B5, com 5 citações. Em seguida, colocam-se os 
periódicos A2 com 3 citações e B4, com 3 citações. Logo após, os periódicos B3 e periódicos sem avaliação do WebQualis, ambos com 2 citações. Com uma citação, consta um periódico de Qualis A1.

A produção acadêmica, segundo Kobashi e Santos (2006) é mais organizada, certificada por pares e controlada pelas instituições universitárias, além de ter a supervisão de um orientador já reconhecido. Deste ponto de vista, ser citado em um trabalho acadêmico confere maior importância, e portanto as dissertações obtêm neste aspecto uma vantagem, pois foram mais citadas em trabalhos acadêmicos do que as teses, e por instituições renomadas como a Universidade Federal do Rio Grande do Sul e a Universidade do Vale do Rio dos Sinos de acordo com o Gráfico 10. Já as teses se encontram mais citadas pelos trabalhos da Universidade do Vale do Rio dos Sinos, com 2 citações feitas nesta instituição.

Gráfico 10 - Instituições vinculadas aos trabalhos acadêmicos

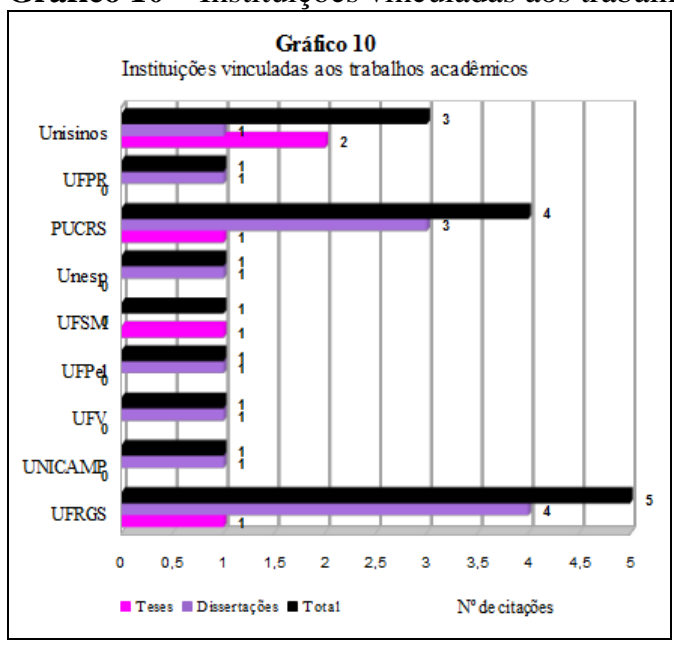

Fonte: dados das autoras.

Em relação aos idiomas dos textos citantes, foi possível verificar que apenas 2 citações não foram feitas em nossa língua nativa, sendo uma em Língua Inglesa, citando uma tese, e a outra em Língua Italiana, citando uma dissertação.

\section{REDES DE CITAÇÃO ENTRE AUTORES}

Os autores citantes apresentados nas redes se diferenciam pelas cores amarela, laranja, vermelha e rosa, respectivamente para representar laços de 1, 2, 3 e 4 citações, indicando a espessura dos laços direcionais. 
As redes de citações das teses foram representadas na Figura 1. Em relação ao grau de centralidade, vemos que a autora da tese $\mathrm{T} 1$ possui bastante relevância na rede, uma vez que "pessoas com maior quantidade de contatos diretos são, certamente, elos importantes em qualquer rede social" (MARTELETO, 2001, p. 75). A Figura 1 representa as relações encontradas entre estes trabalhos.

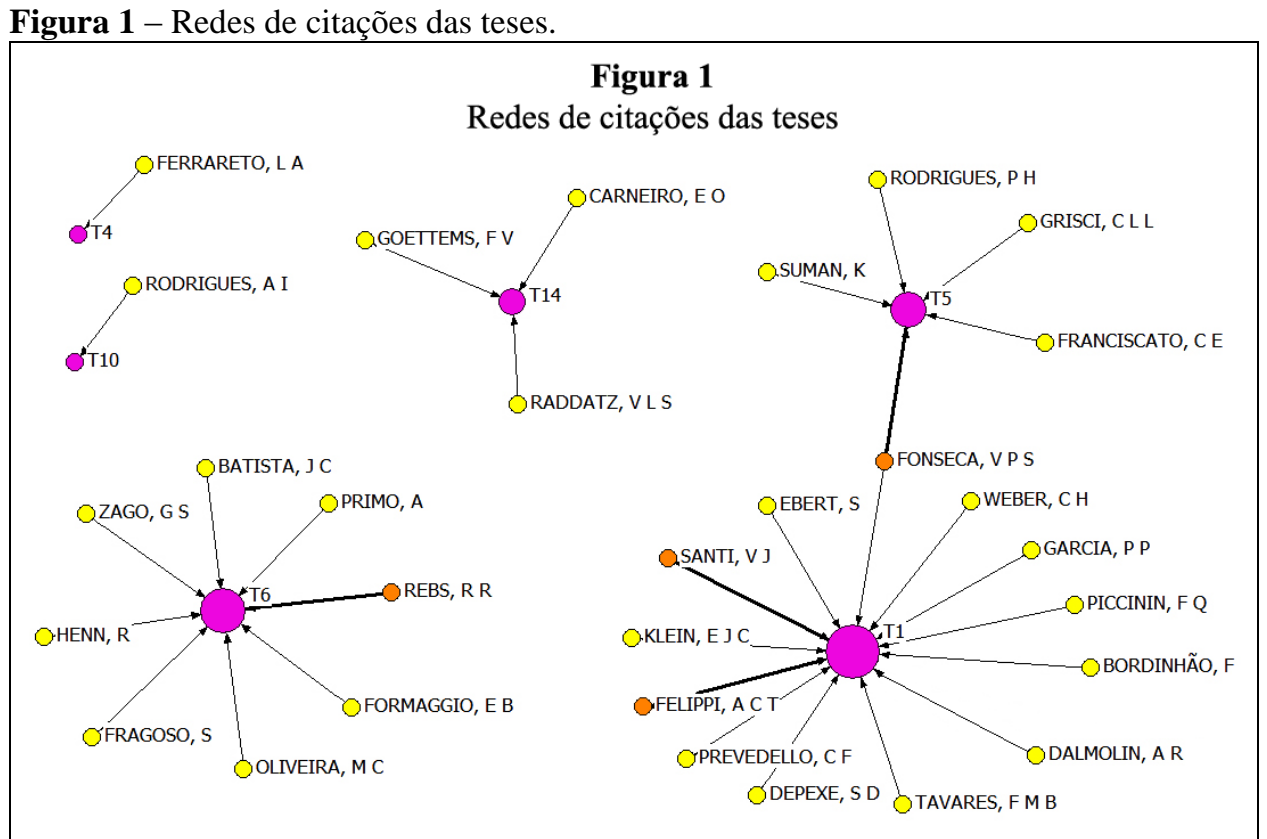

Fonte: dados das autoras.

O nó da T10 constitui uma relação de autocitação, assim como o nó da T4. O uso de autocitações é comum segundo Meadows (1999, p. 90), pois “[...] quando possível, os pesquisadores naturalmente preferem usar trabalhos de sua própria autoria."

O nó da T14 apresenta um laço com Carneiro, com Goettems e uma autocitação. Todos os autores do nó estavam vinculados à Universidade Regional do Noroeste do Estado do Rio Grande do Sul, o que demonstra uma relação institucional.

A T6 possui laços com os autores Formaggio e Oliveira, ambos vinculados à Universidade Federal do Rio grande do Sul, em um trabalho colaborativo apresentado em evento, caracterizando uma relação institucional. Fragoso, Henn e Rebs, vinculados à Universidade do Vale do Rio dos Sinos, citaram a T6 em um trabalho apresentado em evento. Trata-se de uma relação de orientação, uma vez que Fragoso integrara a banca de avaliadores da defesa da tese. Rebs vincula-se com o autor da T6 
também devido a uma citação em um artigo, caracterizando uma relação temática com o trabalho. Primo, orientador do trabalho T6, também o cita em um artigo, constituindo uma relação de orientação. Zago e Batista, ambos bacharéis vinculados respectivamente à Universidade Federal de Pelotas e à Universidade Católica de Pelotas, em colaboração citam a T6 em um artigo, demonstrando uma relação institucional, uma vez que um deles faz parte da instituição de vínculo atual do autor da T6, a Universidade Federal de Pelotas.

A tese T5 possui duas autocitações. A citação de Grisci, da Universidade Federal do Rio Grande do Sul e Rodrigues, da Fundação Roberto Marinho, ocorreu em uma colaboração na produção de um artigo, caracterizando, pelo vínculo de Grisci, uma relação institucional. Suman citou a T5 em sua dissertação pela Universidade do Vale do Rio dos Sinos, demonstrando uma relação temática. Franciscato, vinculado à Universidade Federal de Sergipe, em uma relação também temática citou a T5 em um trabalho apresentado em evento. Fonseca possui relevância na rede, uma vez que liga os nós da T5 e T1, por meio de duas autocitações e uma citação da T1. Devido à dimensão e extensão, estes nós são os mais influentes do mapa das teses.

A T1 detém o maior grau de centralidade da rede. Com a citação do trabalho colaborativo entre Bordinhão e Depexe, vinculados à Universidade Federal de Santa Maria, estabelece uma relação institucional, por se tratar da mesma instituição à qual pertenceu posteriormente o autor da T1. Piccinin, Felippi, Weber, Ebert e Garcia, vinculados à Universidade de Santa Cruz do Sul, citaram o autor da T1 em um trabalho colaborativo, mostrando uma relação temática com a autora, assim como Klein e Tavares, atuantes na Universidade do Vale do Rio dos Sinos, que citaram a autora em um artigo científico. Santi, por sua vez, cita o autor da T1 em sua dissertação pela Universidade Federal de Santa Maria, orientado pelo próprio autor da T1, e posteriormente durante sua atuação na Pontifícia Universidade Católica do Rio Grande do Sul. Ambas as ligações se tratam de relações de orientação. No caso de Prevedello, pode-se deduzir que tenha ocorrido uma relação institucional, uma vez que possuía vínculo com a mesma instituição que o autor da T1. Dalmolin cita a T1 em sua tese pela Universidade do Vale do Rio dos Sinos, tratando-se aparentemente 
de uma relação temática, assim como Felippi, que citou a T1 durante seu Mestrado na Universidade de Santa Cruz do Sul.

As redes de citações das dissertações estão representadas na Figura 2. Pode-se verificar maior grau de centralidade nos nós das dissertações D16 e D30, em diferentes redes.

Figura 2 - Redes de citações das dissertações.

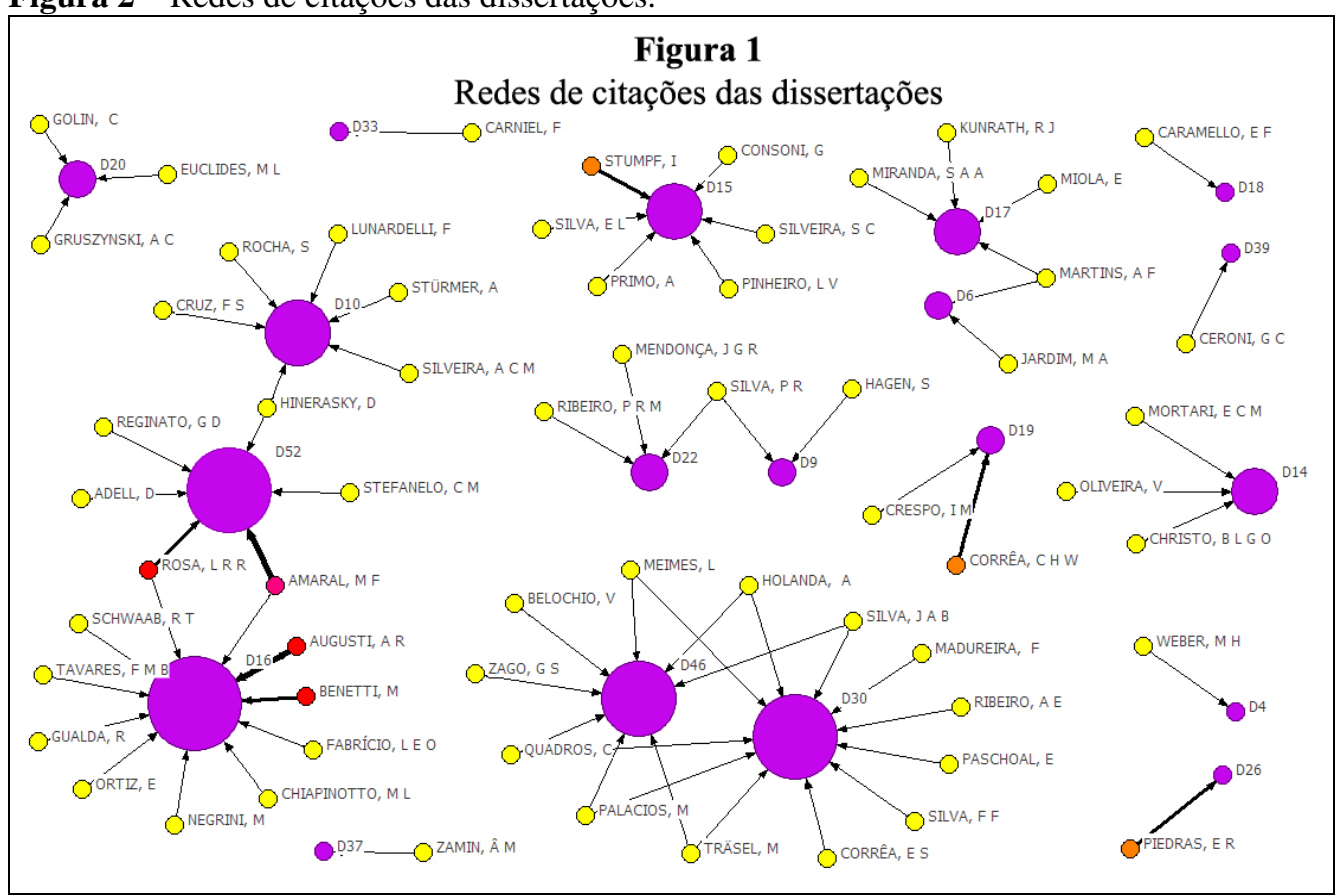

Fonte: dados das autoras.

O nó da D37 mostra um laço com Zamin, que a citou em sua dissertação na Universidade do Vale do Rio dos Sinos, caracterizando uma provável relação temática.

A D39 possui um laço com Ceroni, que a citou em sua dissertação pela Pontifícia Universidade Católica do Rio Grande do Sul, representando uma relação institucional entre os dois autores, uma vez que o autor da D39 posteriormente se vinculou à mesma instituição.

Já a D33 obteve um laço com Carniel, quando este a citou em sua dissertação na Universidade Federal do Paraná, apresentando uma relação temática, uma vez que aparentemente não há relação institucional devido à distância geográfica que se coloca entre os dois autores. 
A D4 possui em seu nó um laço com Weber, a própria orientadora, caracterizando uma relação de orientação.

Nestes primeiros nós percebem-se as chamadas periferias, que embora concentrem menos laços, não são menos importantes, pois geralmente são as vias de abertura para novas relações. (MARTELETO, 2001). Tratam-se de laços que no futuro podem vir a formar outras redes, ou estabelecer outras ligações entre as redes já existentes.

O nó da D26 apresenta um laço duplo de autocitações. A D18 também possui uma autocitação em seu único laço. Segundo Meadows (1999), as autocitações correspondem a aproximadamente $10 \%$ das citações do meio científico, tratando-se de situações normais.

A D15 também possui um laço duplo de autocitações em seu nó, tendo uma destas ocorrido individualmente e outra em colaboração com Crespo, vinculada à Pontifícia Universidade Católica do Rio Grande do Sul. Percebe-se uma provável relação institucional, ressaltando-se a probabilidade de posteriormente terem se tornado parceiras de pesquisa na mesma instituição.

O nó da D9 consiste em uma autocitação em sua dissertação pela Universidade Federal do Rio Grande do Sul, e um laço com Silva, sua orientadora, constituindo uma relação de orientação. Esta ligação merece destaque por estabelecer a conexão com a D22.

A D22 tem em seu nó laços com Silva, em uma relação institucional. A relação de citação com a colaboração de Ribeiro e Mendonça foi temática, pois não foram detectados indícios de outro tipo de relação.

Os laços da D20 a ligam a Euclides em uma relação temática, pois não se identificou outro tipo de relação. Golin e Gruszynski citam a D20 através de uma colaboração em um artigo. O laço de Gruszynski, vinculada à Pontifícia Universidade Católica do Rio Grande do Sul, e Golin, vinculada à Universidade Federal do Rio Grande do Sul, constituem uma relação temática.

O autor da D14 possui um laço com Christo, em uma relação temática, tratando-se de uma citação na sua monografia da Universidade Federal de Viçosa. A relação com Mortari e Oliveira se constitui em uma citação originada de uma 
colaboração em um trabalho apresentado em evento, estabelecendo uma relação temática.

O autor da D15 possui laços com Pinheiro e Silva, pesquisadoras de Santa Catarina, em uma relação temática, pois aparentemente não há outro tipo de relação. Com Stumpf, trata-se de uma relação de orientação, contando com o fato de esta ter feito parte da banca examinadora na defesa da própria D15. Stumpf também cita este trabalho em colaboração com Primo, Consoni e Silveira, tratando-se de uma relação institucional, pois todos os citantes eram vinculados à Universidade Federal do Rio Grande do Sul.

A relação da D10 com Silveira, Stürmer e Lunardelli parece ser geográfica, pois embora Lunardelli estivesse vinculada à Universidade Federal do Rio Grande do Sul e à Universidade do Vale do Rio dos Sinos, as demais estavam vinculadas à Universidade Federal de Santa Maria, na mesma região de atuação do autor da D10 em momento posterior à defesa da dissertação, Santa Maria, no Rio Grande do Sul. Possui também um laço de autocitação em uma colaboração com Cruz e Rocha, na produção de um artigo. Deduz-se que com Rocha se trate de uma relação institucional, uma vez que este esteve vinculado à mesma instituição que o próprio autor citado. Cruz, no entanto, parece estabelecer uma relação temática com a D10, devido à ausência de outros tipos de relações aparentes. O autor da D10 também faz a ponte de ligação entre seu nó e o nó do autor da D52, citando-o em uma relação temática, em colaboração com Stefanelo, vinculada ao Centro Universitário Franciscano.

A D52 possui laços com Adell, vinculado à Universidade de São Paulo (USP), em um trabalho apresentado em evento. Reginato e Amaral, vinculados à Universidade Federal de Santa Maria, o citam em colaboração. Sua rede liga-se à rede do nó do autor da D16 através de Amaral e Rosa. Todas as colaborações parecem ser apenas temáticas em relação à D52, pois não foram constatados outros tipos de relações. Observa-se que entre os pesquisadores da Universidade Federal de Santa Maria o aproveitamento do trabalho é grande, sendo Amaral quem faz maior divulgação desta dissertação. $\mathrm{O}$ autor da D52 não possui maiores relações com a área da Comunicação, pois posteriormente vinculou-se à área da Moda. 
O nó da D16 possui laço triplo com ele mesmo, indicando autocitação. Amaral, sua orientadora, e Rosa, vinculadas à Universidade Federal de Santa Maria, citaram a D16 colaborando em trabalhos apresentados em eventos, fazendo a ligação deste trabalho com a D52. Ambas as citações se constituem como relações temáticas. Possui também um laço duplo com Benetti, vinculada à Universidade Federal do Rio Grande do Sul, que a cita em um artigo e em um trabalho apresentado em evento, mostrando uma relação temática. Com os autores Fabrício, Chiapinotto e Negrini, parece ter existido uma relação temática, pois dos três, dois são vinculados à Universidade Federal de Santa Maria e Fabrício não possuía vínculo institucional. Gualda, atuante em Austin, no Texas, citou a D16 em um artigo, e parece constituir apenas uma relação temática. Ortiz citou a D16 também em uma aparente relação temática em sua monografia pela Universidade Presbiteriana Mackenzie, de São Paulo (SP). A colaboração de Schwaab e Tavares, vinculados respectivamente à Universidade Federal do Rio Grande do Sul e à Universidade do Vale do Rio dos Sinos, em um artigo, mostra uma relação institucional com Schwaab e temática com Tavares.

O nó da D46 possui uma autocitação. Já com Meimes, vinculado à Pontifícia Universidade Católica do Rio Grande do Sul, a relação foi institucional, uma vez que o autor da D46 posteriormente se vinculou à mesma instituição. Zago, filiada à Universidade Católica de Pelotas, e Belochio, filiado à Universidade Federal do Rio Grande do Sul, parecem relacionar-se com o autor da D46 institucionalmente, devido ao local de atuação de Belochio. Já Holanda, Quadros, Silva e Palacios, todos vinculados à Universidade Federal da Bahia, com exceção de Quadros, vinculado à Universidade Tuiuti do Paraná, obtiveram relação temática com a dissertação. Palacios e Quadros mostraram o mesmo tipo de relação com o nó da D30, conectando a D30 à D46.

Por sua vez, a rede da D30, além de ter o laço de intermediação de Holanda, Quadros, Silva, Palacios, Meimes e o autor da D46, possui também um laço de relação temática com o jornalista Paschoal, em uma citação online. Corrêa e Madureira, ambos vinculados à Universidade de São Paulo, também estabelece uma relação temática com o autor da D30. Ribeiro, Doutora vinculada ao Centro Federal 
de Educação Tecnológica de Minas Gerais, constitui uma relação temática citando a D30 em um trabalho apresentado em evento.

Verifica-se de um modo geral uma considerável incidência de autocitações. Isto não prejudica a análise dos indicadores, pois trata-se de uma situação normal, visto que a ausência de autocitações pode indicar falta de originalidade, enquanto autocitações constantes podem refletir isolamento e falta de comunicação do pesquisador. (GLÄNZEL, 2003).

\section{CONSIDERAÇÕES FINAIS}

A partir dos resultados, verifica-se que a produção acadêmica do programa de pós-graduação analisado esteve contribuindo para novas produções científicas nos últimos anos. Os trabalhos mais citados foram os referentes à área da Comunicação, cuja área é também a mais produtiva dentro do programa. O tempo médio entre a publicação e citação dos trabalhos fica na média esperada em relação aos padrões para artigos científicos. Considera-se positivo que os trabalhos sejam mais citados em publicações de Qualis B2, pois isto relaciona a literatura acadêmica do programa à qualidade. Os maiores disseminadores dos trabalhos analisados estão em sua maioria vinculados à Universidade Federal do Rio Grande do Sul, e acabaram promovendo também as relações intra-institucionais na universidade.

Salienta-se a importância de optar por bases de dados alternativas em estudos bibliométricos, como o Google e o Google Acadêmico, uma vez que este estudo não teria sido possível de ser concretizado em bases de dados tradicionais como a Web of Science e Scopus, devido à falta citações dos trabalhos estudados nestas bases.

Constata-se que as teses e dissertações do Programa de Pós-Graduação em Comunicação e Informação estão visíveis, mas ainda carecem de citações em grandes bases de dados para estarem ao alcance de um maior número de pesquisadores. Assim, sugere-se a elaboração de estudos sobre estratégias de marketing para a produção científica acadêmica, a fim de se elucidar a melhor forma de divulgar a informação indexada em repositórios institucionais. 


\section{REFERÊNCIAS}

BUFREM, Leilah; PRATES, Yara. O saber científico registrado e as práticas de mensuração da Informação. Ciência da Informação, Brasília, DF, v. 34, n. 2, p. 9-25, maio/ago. 2005.

CALLON, Michel; COURTIAL, Jean-Pierre; PENAN, Herve. Cienciometría: el estudio cuantitativo de la actividad científica: de la bibliometria a la vigilancia tecnologica. Asturias: TREA, 1995.

CASTRO, Cláudio Moura. Ciência e Universidade. Rio de Janeiro: Jorge Zahar, 1985.

GLÄNZEL, Wolfgang. Bibliometrics as a research field. [S.l.: s.n.], 2003.

KOBASHI, Nair Yumiko; SANTOS, Raimundo Nonato Macedo dos.

Institucionalização da pesquisa científica no Brasil: cartografia temática e de redes sociais por meio de técnicas bibliométricas. TransInformação, Campinas, v. 1, n. 18, p. 27-36. jan./abr. 2006.

MACIAS-CHAPULA, Cesar A. O papel da informetria e da cienciometria e sua perspectiva nacional e internacional. Ciência da Informação, Brasília, DF, v. 27, n. 2, p.134-140. maio/ago. 1998.

MALTRÁS-BARBA, Bruno. Los indicadores bibliométricos: fundamentos y aplicación al análisis de la ciencia. Asturias: TREA, 2003.

MARTELETO, Regina Maria. Análise de redes sociais: aplicação nos estudos de transferência da informação. Ciência da Informação, Brasília, DF, v. 30, n. 1, p. 7181. jan./abr. 2001.

MEADOWS, A. J. A Comunicação Científica. Brasília, DF: Briquet de Lemos, 1999.

POBLACIÓN, Dinah Aguiar; WITTER, Geraldina Porto; SILVA, José Fernando Modesto. Comunicação \& produção científica: contexto, indicadores e avaliação. São Paulo: Angellara, 2006.

Mugnaini, Rogério; Carvalho, Telma de; Campanatti-Ostiz, Heliane. Indicadores de produção científica: uma discussão conceitual. In: Población, D. A.; Witter, G. P.; Silva, J.F.M. (org.). Comunicação e produção científica: contexto, indicadores, avaliação. São Paulo: Angellara Editora, 2006. p.313 - 340.

PACKER, Abel L; MENEGHINI, Rogério. Visibilidade da produção científica. In: Población, D. A.; Witter, G. P.; Silva, J.F.M. (org.). Comunicação e produção científica: contexto, indicadores, avaliação. São Paulo: Angellara Editora, 2006. p. 236-259.

PORTO, Claudio; RÉGNIER, Karla. O ensino superior no mundo e no Brasil: condicionantes, tendências e cenários para o horizonte 2003-2025: uma 
abordagem exploratória. Cáceres: UNEMAT, 2003. Disponível em:

$<$ http://www.unemat.br/prpdi/pdi/docs/ensino_superior_mundo_brasil_tendencias_ce narios_2003_2025.pdf>. Acesso em: 7 out. 2011.

ROUSSEAU, Ronald. Indicadores bibliométricos e econométricos para a avaliação de Instituições Científicas. Ciência da Informação, Brasília, DF, v. 27, n. 2, p. 149-158, maio/ago. 1998.

SANTOS, Raimundo Nonato Macedo. Produção científica: por que medir? O quê medir? Revista Digital de Biblioteconomia e Ciência da Informação, Campinas, v . 1, n. 1, p. 22-38, jul./dez. 2003.

SPINAK, Ernesto. Indicadores cienciometricos. Ciência da Informação, Brasília, DF, v. 27, n. 2, p. 141-148, maio/ago. 1998.

TRZESNIAK, Piotr. As Dimensões da qualidade dos periódicos científicos e sua presença em um instrumento da área da educação. Revista Brasileira de Educação, Rio de Janeiro, v. 11, n. 32, p. 346-377. maio/ago. 2006.

VANZ, Samile Andréa de Souza. CAREGNATO, Sonia Elisa. Estudos de citação: uma ferramenta para entender a comunicação científica. Em Questão, Porto Alegre, v. 9 , n . 2, p. 295-307, jul. /dez. 2003.

\section{Como citar este artigo:}

NUNEZ, Zizil Arledi Glienke; MOURA, Ana Maria Mielniczuk de. Análise de citações na área de comunicação e informação: o caso de um programa de pósgraduação. Rev. digit. bibliotecon. cienc. inf., Campinas, SP, v. 11, n. 2, p.40-60 , maio/ago. 2013. ISSN 1678-765X. Disponível em: <http://www.sbu.unicamp.br/seer/ojs/index.php/rbci> 